\title{
Concepções e conhecimento sobre amamentação de profissionais da atenção básica à saúde ${ }^{1}$
}

\section{Professional's concepts and knowledge of the primary health care services about breast feeding}

\section{Concepciones y conocimiento sobre amamentación de profesionales de la atención básica de salud}

\section{Cássia Irene Spinelli Arantes', Aida Victoria Garcia Montrone", Debora Brechesi Milioni"I}

\section{RESUMO}

Os objetivos foram descrever e analisar concepções e conhecimento sobre amamentação de profissionais de nível superior que atuam na atenção básica à saúde de São Carlos-SP. Estudo descritivo e exploratório, cujos dados foram obtidos por entrevista semiestruturada com 54 profissionais. Foi utilizado o método qualitativo de análise temática para apreensão das concepções. Os conhecimentos dos profissionais foram analisados por freqüência simples no programa Epi-Info. As concepções permearam quatro temáticas: amamentação é saúde para a criança; amamentação é vínculo entre mãe e filho; amamentação é um ato de baixo custo; as ações voltadas à amamentação na atenção básica precisam avançar. O percentual médio de acerto nas questões de conhecimento entre as categorias foi: enfermeiras, 92,2\%; médicos pediatras, $88.1 \%$; médicos de família, $86,7 \%$ e médicos ginecologistas e obstetras, $63,6 \%$. 0 maior percentual de acerto foi sobre o uso de chupetas. Os erros mais freqüentes foram quanto à duração e freqüência das mamadas. As concepções estão voltadas aos benefícios que a amamentação proporciona para a saúde da criança e aos aspectos afetivos e sociais positivos. Enfermeiras e médicos pediatras demonstraram melhor desempenho no teste de conhecimento.

Palavras chave: Aleitamento materno; Amamentação; Atenção primária à saúde; Recursos humanos em saúde.

\section{ABSTRACT}

The objectives were to describe and analyze concepts and knowledge about breast-feeding from top-level professionals who work in primary health care services in the city of San Carlos-SP. Descriptive and exploratory study, whose data were obtained by semi-structured interviews with 54 professionals. To collect the conceptions we employed the qualitative method of thematic analysis. The data on the professionals' knowledge were analyzed by simple frequency in the Epi-Info program. The conceptions comprehended four themes: breast-feeding means health for the child; breast-feeding is a bond between mother and child; breast-feeding is an act of low cost, and actions for breast-feeding in primary care services need to advance. The average percentage of accurate responses in matters of knowledge among the categories was: nurses, 92.2\%; pediatricians, $88.1 \%$; family practitioners, $86.7 \%$ and medical obstetricians and gynecologists, $63.6 \%$. The highest percentage of success was about the use of pacifiers. The most frequent errors were about the duration and frequency of breastfeeding. The conceptions are dedicated to the benefits that this practice provides for a child's health and for the positive social and emotional aspects. Nurses and pediatricians were the best performing categories in the test of knowledge.

Key words: Breast feeding; Primary health care; Health manpower.

\footnotetext{
Pesquisa contemplada por uma bolsa do Programa Institucional de Bolsas de Iniciação Científica (PIBIC) do Conselho Nacional de Desenvolvimento Científico e Tecnológico (CNPq) e da Universidade Federal de São Carlos (UFSCar), de agosto de 2005 a julho de 2006.

' Enfermeira. Doutora em Enfermagem. Professor Associado do Departamento de Enfermagem da Universidade Federal de São Carlos (UFSCar). São Carlos, SP. Email: arantes@ufscar.br

"Enfermeira. Doutora em Educação. Professor Adjunto do Departamento de Metodologia de Ensino da UFSCar. São Carlos, SP. Email: montrone@ufscar.br

III Enfermeira. Mestranda em Enfermagem da UFSCar. Bolsista do PIBIC/CNPq/UFSCar, de agosto de 2005 a julho de 2006. São Carlos, SP. Email: deboramilioni@hotmail.com
} 


\section{RESUMEN}

Los objetivos fueron describir y analizar concepciones y conocimiento sobre amamentación de profesionales de nivel superior que actuan en la atención básica de salud de São Carlos-SP. Estudio descriptivo y exploratório, cuyos datos fueron obtenidos por entrevista semi-estructurada con 54 profesionales. Fue utilizado el método cualitativo de análisis temática para comprender las concepciones. Lo conocimientos de los profesionales fueron analisados por frecuencia simples en el programa Epi-Info. Las concepciones resultaron en cuatro temáticas: amamentación és salud para el niño; amamentación és vínculo entre madre e hijo; amamentación és un acto de bajo costo; las acciones dirigidas a la amamentación en la

\section{NTRODUÇÃO}

Apesar de nas últimas décadas ter ocorrido um aumento na prevalência do aleitamento materno no Brasil, o desmame precoce ainda continua a ocorrer de forma significativa. O país ainda está longe de atender à recomendação da Organização Mundial da Saúde (OMS) e do Ministério da Saúde, de amamentação exclusiva até os seis meses e amamentação com alimentos complementares até os dois anos de idade ou mais $^{(1)}$.

A tendência crescente da freqüência da amamentação no país, nos últimos 25 anos do século $X X$, foi comprovada pela análise dos resultados de três pesquisas realizadas em momentos diferentes: 1974-1975, 1989 e 1999, demonstrando que entre a primeira e a terceira pesquisa o incremento da prevalência do aleitamento materno correspondeu a $40 \%$ no grupo de crianças com um mês, a $150 \%$ no quarto mês e a $200 \%$ no sexto mês de vida ${ }^{(2)}$.

No final da década de 90, a maioria dos bebês $(96,4 \%)$ saía da maternidade sendo amamentada, porém, somente $40 \%$ deles permaneciam em aleitamento materno exclusivo até os quatro meses de idade ${ }^{(3)}$. Em pesquisa realizada junto a 84 municípios do estado de São Paulo, no ano de 1998, detectouse que em apenas 27 municípios a amamentação exclusiva em crianças menores de quatro meses, foi superior a $20 \%$ e em pouquíssimos municípios alcançaram-se índices superiores a $30 \%^{(4)}$. Na cidade de São Carlos, atención básica necesitan avanzar. El porcentaje médio de respuestas correctas en las cuestiones de conocimientos entre las categorias fue: enfermeras, $92,2 \%$; médicos pediatras, $88.1 \%$; médicos de família, $86,7 \%$ y médicos ginecologistas y obstetras, $63,6 \%$. El mayor porcentaje de respuestas correctas fue sobre el uso de chupetes. Los errores mas frecuentes fueron con relación a la duración y frecuencia de las mamadas. Las concepciones estan direccionadas a los benefícios que la amamentación proporciona a la salud del niño y a los aspectos afectivos y sociales positivos. Enfermeras y médicos pediatras demuestraran mejor desempeño en el test de conocimiento.

Palabras clave: Lactancia materna; Atención primaria de salud; Recursos humanos en salud.

São Paulo, um estudo realizado em 1998, mostrou que aos cinco meses de idade, 50\% das crianças já estavam completamente desmamadas ${ }^{(5)}$.

Rego ${ }^{(6)}$ aponta como causa do desmame precoce, a desinformação da população em geral e, especialmente, dos profissionais da área de saúde. Afirma, ainda, que o motivo alegado para o desmame é a recomendação da própria equipe de saúde em $31,4 \%$ dos casos, comparável aos $31,5 \%$ de mães que abandonam a amamentação alegando que "o leite não sustenta", evidenciando a importância da capacitação dos profissionais de saúde para incrementar a prevalência do aleitamento materno.

A falta de apoio dos serviços de saúde é uma das causas das dificuldades com a amamentação e nessa perspectiva, considerando o relevante papel das unidades de atenção básica à saúde, na assistência às gestantes, puérperas e bebês, em 2002, o Ministério da Saúde adotou como estratégia nacional, a proposta Iniciativa Unidade Básica Amiga da Amamentação - IUBAAM. Essa iniciativa delineia um importante papel de suporte que as unidades básicas de saúde, em conjunto com os hospitais, podem desempenhar a fim de tornar o aleitamento materno uma prática universal e contribuir significativamente para a saúde e bem estar dos bebês, suas mães, família e comunidade local ${ }^{(7)}$. 
Os baixos índices de aleitamento na cidade de São Carlos e a inexistência de serviços organizados que visassem à promoção, apoio e proteção ao aleitamento materno, levaram a Secretaria Municipal de Saúde, no final de 2003, a iniciar a implantação de uma série de medidas, dentre elas a de que as unidades de saúde se estruturassem com base nos passos delineados pela IUBAAM.

As ações de incentivo, promoção e apoio ao aleitamento materno devem ocorrer no conjunto das ações dos profissionais, durante o pré-natal, o pré-parto, o nascimento, assim como nas imunizações, teste do pezinho e retorno para a consulta de puerpério. É essencial que a equipe de saúde tenha o papel de acolhimento de mães e bebês, disponível para escuta e para o esclarecimento de dúvidas e aflições, incentivando a troca de experiências e disponibilizando, sempre que necessário, uma avaliação singular de cada caso ${ }^{(8)}$.

$O$ apoio aos casais que vivenciam o processo de lactação deve ser contínuo durante todo o período da amamentação. Para tal, é fundamental que os profissionais de saúde estejam atualizados em seus conhecimentos e condutas para desenvolverem essas atividades de forma eficiente.

Um estudo com equipes que atuam em atenção básica - Programa de Saúde da Família apontou que os profissionais possuíam muitos conhecimentos quanto às vantagens da amamentação, mas apresentaram um desempenho pouco satisfatório com relação a procedimentos essenciais para o manejo clínico da lactação(9).

Tendo em vista a importância que os profissionais de saúde possuem na implantação de ações de promoção, proteção e apoio ao aleitamento materno, este estudo teve como objetivo analisar as concepções e conhecimento sobre amamentação dos profissionais que atuam nas unidades de atenção básica à saúde do município de São Carlos. Procuramos conhecer como os profissionais percebem 0 aleitamento materno e ao mesmo tempo identificar as possíveis lacunas de conhecimento existentes entre eles, com vistas ao planejamento de capacitações.

\section{METODOLOGI A}

Foi realizado um estudo descritivo e exploratório, com abordagem qualitativa e quantitativa de análise de dados, focalizando as concepções e os conhecimentos sobre a amamentação dos profissionais de nível superior que atuam na atenção básica à saúde.

A abordagem qualitativa foi adotada na análise dos dados referentes às concepções dos profissionais sobre a amamentação. Tal abordagem se propõe a abarcar o conhecimento da realidade social que é exterior ao sujeito, bem como as representações sociais que traduzem o mundo dos significados ${ }^{(10)}$.

A abordagem quantitativa foi utilizada no tratamento dos dados referentes às variáveis sobre a caracterização dos profissionais e os seus conhecimentos sobre amamentação. Foram estabelecidas previamente as seguintes variáveis: categoria profissional, sexo, idade, possuir ou não filhos, filhos amamentados, tempo de trabalho na equipe atual, participação em cursos sobre amamentação, auto-avaliação quanto aos conhecimentos na área, importância de se lavar os mamilos após a mamada, importância de se trocar de mama após cerca de 10 minutos, necessidade de o bebê ser amamentado com regularidade de horários, uso de chupetas e a amamentação, composição do leite materno ao longo da mamada, necessidade de complementação se não ocorrer a apojadura em até três dias após o parto, necessidade de complementação se houver diminuição da produção láctea e benefício da luz solar para a prevenção de trauma mamilar.

A população de estudo se constituiu de 80 profissionais de nível superior (30 médicos pediatras, 24 médicos ginecologistas e obstetras, 20 enfermeiras e 6 médicos de família) atuantes em todos os serviços de atenção básica existentes na zona urbana de São Carlos - SP, em dezembro de 2005 - 13 unidades básicas de saúde e 6 unidades de saúde da família. A amostra foi constituída por todos os profissionais que aceitaram participar da pesquisa e que estavam em atividade profissional nas unidades de estudo durante o período em que ocorreu a coleta dos dados, nos meses de dezembro de 2005 e janeiro de 2006. Foram excluídos os profissionais que estavam em férias ou licença. 
Os dados foram coletados por meio de entrevista, utlizando-se um roteiro semiestruturado. Utilizamos neste trabalho as informações oriundas de duas questões abertas sobre as concepções dos profissionais de saúde: 1) O que é amamentação para você? 2) Como você vê a prática dos profissionais de saúde na promoção e apoio à Amamentação nos serviços de atenção básica à saúde? Foram analisados, ainda, os dados referentes a oito perguntas fechadas sobre a caracterização da amostra e, também, as respostas de um teste com 8 questões tipo verdadeiro ou falso sobre o conhecimento dos profissionais sobre amamentação. As entrevistas tiveram uma duração média de 8 minutos e foram realizadas por uma das pesquisadoras que fazia as perguntas e registrava as respostas.

Dos 80 profissionais atuantes, 61 foram abordados e convidados a participar da pesquisa durante o seu horário de trabalho, nas respectivas Unidades de Saúde, antes ou após suas atividades diárias. Destes, 54 aceitaram participar, assinando o termo de consentimento livre e esclarecido. Foram entrevistados: 19 médicos pediatra, 16 enfermeiras, 13 médicos ginecologista e obstetra e 6 médicos de família.

$\mathrm{Na}$ análise qualitativa sobre as concepções referentes à amamentação, optamos por analisar as entrevistas de uma forma geral, sem identificação da categoria do profissional. As entrevistas foram numeradas por ordem de realização. No material empírico, buscamos apreender o significado da amamentação para os profissionais, bem como a sua percepção quanto à prática profissional nesta área nas unidades de atenção básica à saúde. Foram adotados os seguintes passos: ordenação dos dados, através do seu mapeamento; classificação dos dados, pela leitura exaustiva do material para identificação de temas relevantes e estabelecimento de categorias temáticas; análise final, por meio da realização de articulações entre os dados e os referenciais teóricos ${ }^{(11)}$. Identificamos e analisamos quatro temáticas: Temática I: Amamentação é saúde para a criança; Temática II: Amamentação é vínculo entre mãe e filho; Temática III: Amamentação é um ato de baixo custo; Temática IV: As ações voltadas à amamentação na atenção básica precisam avançar.
A análise quantitativa dos dados obtidos sobre as características e os conhecimentos dos profissionais foi realizada de acordo com os seguintes passos: classificação do material segundo as variáveis; inserção e armazenamento dos dados em banco de dados; e análise de freqüência simples, por meio do programa Epi-Info 2000, versão 3.2 para Windows.

Este trabalho foi autorizado pela Secretaria Municipal de Saúde de São Carlos e aprovado pelo Comitê de Ética de Pesquisa com Seres Humanos da Universidade Federal de São Carlos (parecer no 213/2005).

\section{RESULTADOS E DISCUSSÃO}

\section{Perfil dos Profissionais}

Dos 54 profissionais entrevistados, 53,7\% são do sexo feminino e $46,3 \%$ ao sexo masculino.

Como mostra a Tabela 1, a média da idade dos profissionais é de 41 anos, sendo os médicos de família a categoria mais jovem. O menor tempo médio de atuação na equipe de saúde foi apresentado também pelos médicos de família e se deve, provavelmente, à recente implantação de algumas unidades de saúde da família no município. Mais de dois terços dos profissionais possuem filhos, sendo que a maioria destes recebeu leite materno por algum tempo. 
Tabela 1: Distribuição dos profissionais da atenção básica por categoria, segundo idade, tempo na equipe, filhos e filhos amamentados, São Carlos, 2006.

\begin{tabular}{|c|c|c|c|c|c|}
\hline $\begin{array}{l}\text { Categoria } \\
\text { profissional }\end{array}$ & $\mathbf{N}$ & $\begin{array}{l}\text { I dade (média } \\
\text { em anos) }\end{array}$ & $\begin{array}{l}\text { Tempo na } \\
\text { equipe (média } \\
\text { em anos) }\end{array}$ & Com filhos (\%) & $\begin{array}{c}\text { Filhos } \\
\text { amamentados } \\
(\%)\end{array}$ \\
\hline Enfermeira & 16 & 39 & 52,9 & 62,5 & 90 \\
\hline $\begin{array}{l}\text { Médico Pediatra } \\
\text { Médico }\end{array}$ & 19 & 46,2 & 85,9 & 84,2 & 93,8 \\
\hline $\begin{array}{l}\text { Ginecologista e } \\
\text { obstetra }\end{array}$ & 13 & 42,1 & 90 & 69,2 & 77,8 \\
\hline Médico de Família & 6 & 36,8 & 11,2 & 50 & 100 \\
\hline TOTAL & 54 & 41 & 68,8 & 70,4 & 89,5 \\
\hline
\end{tabular}

Na Tabela 2 podemos observar que 38,9\% dos profissionais entrevistados nunca realizaram qualquer capacitação ou curso sobre amamentação. $O$ que se mostrou mais preocupante foi o resultado encontrado junto aos médicos ginecologistas e obstetras, pois a expressiva maioria dos profissionais entrevistados desta categoria $(84,6 \%)$ relatou não ter participado de qualquer treinamento em amamentação. Tendo em vista que o conhecimento é essencial para que os profissionais incentivem, orientem e apóiem efetivamente as mulheres e suas famílias durante o processo de lactação; há necessidade de que esses profissionais busquem cursos de atualização e, principalmente, que o gestor municipal promova cursos de educação continuada e incentive a participação de todos os profissionais que atuam no âmbito da atenção básica à saúde. Para Bassichetto, Rea ${ }^{(12)}$ os profissionais de saúde apresentam dificuldades para se atualizarem em relação à alimentação infantil, especialmente pela falta de investimento da rede pública em treinamentos, pois a pressão para o atendimento à demanda torna os gestores pouco sensíveis a propostas e experiências no campo da educação permanente, principalmente se não vêem claros resultados práticos.

Tabela 2: Capacitações realizadas em amamentação, por categoria profissional. São Carlos, 2006.

\begin{tabular}{ccccccc}
\hline Categoria profissional & \multicolumn{2}{c}{ Nunca } & \multicolumn{2}{c}{$\mathbf{1}$ vez } & \multicolumn{2}{c}{$\mathbf{2}$ vezes ou mais } \\
& $\mathbf{N}$ & $\mathbf{\%}$ & $\mathbf{N}$ & $\mathbf{\%}$ & 5 & $\mathbf{N}$ \\
\hline Enfermeira & 0 & 0 & 8 & 50 & 8 & 50 \\
Médico Pediatra & 7 & 36,8 & 1 & 5,3 & 11 & 57,9 \\
Médico Ginecologista e obstetra & 11 & 84,6 & 0 & 0 & 2 & 15,4 \\
Médico de Família & 3 & 50 & 2 & 33,3 & $\mathbf{2 2}$ & $\mathbf{4 0 , 7}$ \\
\hline TOTAL & $\mathbf{2 1}$ & $\mathbf{3 8 , 9}$ & $\mathbf{1 1}$ & $\mathbf{2 0 , 4}$ &
\end{tabular}

Na auto-avaliação dos profissionais quanto a serem ou não capacitados para observar uma mamada e orientar a mãe para melhorar a técnica de amamentação, a maioria dos entrevistados $(94,4 \%)$ se auto-avaliaram capazes de orientar adequadamente as mães. Este resultado foi semelhante com o encontrado em um outro estudo realizado em diferentes cidades do país, no qual $95,1 \%$ dos profissionais de nível superior que atuavam em PSF declararam-se aptos para orientar a mãe em relação à amamentação(9). As categorias com o maior percentual de avaliações positivas foram a de médico pediatra e médico de família, nas quais $100 \%$ dos profissionais disseram possuir capacitação técnica para tal atividade. Os médicos ginecologistas e obstetras apresentaram a menor proporção de autoavaliação positivas, $84,6 \%$.

Apesar de grande parte dos profissionais jamais ter realizado curso ou treinamento em amamentação, a expressiva maioria dos entrevistados neste estudo se declararam aptos a observar uma mamada e orientar quanto à técnica de amamentação. É possível que os profissionais se atualizem por meio de outras formas de aprendizagem ou se sentem preparados com o conhecimento adquirido durante sua formação profissional. No entanto, Becker (9) afirma que estudo da OMS indicou 
que treinamentos específicos na área de promoção e apoio à amamentação são fundamentais para uma prática correta e efetiva.

\section{Concepções dos profissionais sobre amamentação \\ Temática I: Amamentação é saúde para a criança}

A amamentação com um significado de saúde e vida de uma forma ampla foi apreendida nas respostas de alguns profissionais entrevistados.

Amamentação pra mim é saúde [...]. (24)

[...] eu acho que resume em saúde [...] a primeira palavra em amamentação [...] (07)

Pra mim amamentação é o sentido da vida. (33)

Também evidenciamos um sentido de saúde especificamente voltado aos benefícios que a amamentação proporciona para a criança. Amamentação é saúde total. Criança que amamenta não fica doente. Existe um velho ditado: a criança amamentada raramente adoece e nunca falece. (30)

Amamentação é o modo que a mãe passa maior saúde pro recém-nato [...]. (44)

Dentre os benefícios para a saúde da criança, grande parte dos profissionais destacou a importância da amamentação para a sua saúde nutricional e imunológica, exemplificada nas falas abaixo:

[...] é uma forma de você evitar um grande problema que é a desnutrição e hoje em dia, a gente sabe que amamentar exclusivamente ao seio materno, no mínimo até o 60 mês de vida é uma forma de prevenir doenças sérias no futuro como hipertensão, como problemas cardíacos, como alergias respiratórias e alergias alimentares, inclusive [...]. (15)

Bom, amamentação é o componente nutricional, o componente imunológico [...]. (17)

[...] é importantíssimo [...] por nutrição pra criança [...] que essa criança cresça bem, se fortaleça, receba anticorpos e tenha condição de se prevenir um monte de doenças que acontecem nesse período inicial da vida da criança. (34)

[...] é o modo que a mãe passa maior saúde pro recém-nato, em nível de nutrição, anticorpos (igA, IgG, IgM) [...]. (44)
A amamentação com o significado de proporcionar saúde para a criança, muito enfatizada pelos profissionais em suas falas, expressa o discurso da literatura técnicocientífica que é amplamente divulgado por diferentes autores da área ${ }^{(13-14)}$.

Alguns profissionais entrevistados se restringiram de tal modo à descrição técnica da amamentação que a caracterizaram como o ato de a mãe dar o peito ao seu filho durante um período de tempo.

Amamentação é o ato da mãe, puérpera, oferecer o leite materno para seu filho nas melhores condições e pelo maior tempo possível, no mínimo 6 meses exclusivo, 2 anos complementando. (10)

Amamentação pra mim é o ato da mãe oferecer o seu leite ao seu filho durante o período em que ele necessita desse leite. (20)

[...] é o período que compreende desde o nascimento da criança que ela vai ficar no peito, mamando no seio materno até enquanto for possível [...] pelo menos, pode ser dar, exclusivamente, até os seis meses de idade (46)

Acreditamos que 0 ato de amamentar envolve "muito mais do que a simples passagem de leite de um organismo para outro, ainda que diretamente ao seio" (6).

Nesta temática, observamos entre os profissionais entrevistados uma concepção técnica e tradicional da amamentação notadamente voltada às vantagens que a amamentação traz para a criança.

\section{Temática II: Amamentação é vínculo entre mãe e filho}

A amamentação para os profissionais é uma prática geradora de vínculo entre mãe e filho.

[...] significa criar uma unidade mãe-filho [...] unidade de pessoas que estão, assim, bem integradas. (03)

Bom, amamentação gera um vínculo entre mãe e filho [...]. (14)

É o contato entre mãe e filho... (12)

[...] é uma forma, também, de aumentar o vínculo do bebê com a mãe... (15)

Amamentação é o primeiro vínculo entre mãe e filho. (48) 
De fato a amamentação é um processo que envolve 0 entrosamento entre dois indivíduos, um que amamenta (a mãe) e outro que é amamentado (a criança) e esse entrosamento desencadeia "uma gama de interações facilitadoras da formação do vínculo mãe-filho" (6).

Esse vínculo é caracterizado pelos profissionais como contato e atitudes afetivas entre mães e filhos.

[...] dá segurança pra criança e cria um laço, um afeto [...]. (04)

Amamentação é um ato de doação mesmo, da mãe com o seu filho. Ela dá tudo de bom pro seu filho, carinho, afeto [...] nos primeiros meses de vida. (43)

É um ato de carinho, primeiro contato da mãe com o filho, formando um vínculo de afeto e carinho. É um momento único. (45)

[...] amamentação significa o contato íntimo com a criança [...] contato corpo-a-corpo e isso traz segurança tanto pra a criança quanto pra mãe [...]. (53)

É consenso que a amamentação possibilita o estabelecimento e fortalecimento do vínculo afetivo entre mãe e filho, mas, por outro lado, no campo afetivo, não são somente sentimentos positivos que a amamentação pode proporcionar principalmente para a mulher. Apesar de vários estudos (15-17) já terem apontado que a amamentação pode trazer para a mulher a vivência de sentimentos negativos, como: dor, culpa, angústia, ambigüidade, privação da liberdade, resignação entre outros, na ótica dos profissionais continuam a aparecer somente os sentimentos positivos que a interação mãe-bebê propiciam.

\section{Temática III: Amamentação é um ato de baixo custo}

Apreendemos nas falas dos profissionais o significado da amamentação como uma prática de custo financeiro muito inferior ao aleitamento artificial, significando economia para as famílias

[...] significa alimentação pura, simples, barata [.. ]. (39)

[...] além do custo, que é muito mais barato a mãe amamentar do que comprar latinha de leite [...]. (14)
[...] não gera custos pra família, e principalmente família carente... (16)

$$
\text { Esta temática nos remete }
$$

necessariamente à dimensão social da amamentação, pois o alto custo da alimentação artificial é particularmente importante para os paises em desenvolvimento, que somado ao risco de contaminação no preparo de fórmulas lácteas e/ou as diluições inadequadas podem levar uma parcela significativa de crianças à desnutrição(1).

Análise sobre o custo da alimentação de bebês aponta que, independente do poder aquisitivo da família, o leite materno propicia às crianças pobres e ricas a mesma oportunidade de receber $o$ melhor alimento que existe, permitindo a todas, chances semelhantes de sobrevivência nos primeiros tempos de vida ${ }^{(14)}$.

As concepções sobre amamentação dos profissionais entrevistados, de uma forma geral, enfocaram as vantagens e benefícios que trazem a prática de amamentar. É certo que a amamentação produz inúmeros benefícios que não se restringem somente às crianças, mas beneficia também as mulheres, as famílias e a sociedade, pois ao diminuir o índice de doenças, de internações e de uso de medicação, resulta em melhores condições de saúde da população.

Porém, nos tempos atuais, espera-se dos profissionais de saúde uma visão mais realista da amamentação para que possam atuar com as dificuldades que comumente ocorrem nessa prática; pois somente a exaltação desses benefícios não tem determinado um aumento significativo da amamentação exclusiva, pois o desmame precoce continua a ocorrer de forma predominante, ainda que as investigações mostrem uma elevação da prática de amamentar nas três últimas décadas.

\section{Temática IV: As ações voltadas à amamentação na atenção básica precisam avançar}

$\mathrm{Na}$ visão dos profissionais participantes do estudo, as ações de promoção à amamentação nas unidades de atenção básica à saúde de São Carlos têm melhorado.

Melhorou bastante através de treinamentos e sensibilizações que a gente anda fazendo. A gente tá há um ano ou mais com o Grupo de Aleitamento Materno, o GAAM, e nós fazemos 
sensibilizações pra todos os funcionários, independente, da categoria profissional. (11)

Melhorou muito, a atenção básica hoje tá voltada de uma forma muito importante pra treinamento [...] cada dia eu vejo, uma maior participação do grupo de enfermagem e maior interesse dos médicos também [...]. (13)

Eu acho que, de um tempo pra cá, tem melhorado, principalmente, a conscientização dos profissionais. [...] eles melhoraram bem em incentivo à amamentação. (16)

[...] No começo eu daria nota 5, hoje eu já daria uma nota 8 , porque a promoção e a insistência da amamentação cresceu muito, inclusive nos programas, nas propagandas, tudo. (39)

Apesar do reconhecimento de que melhorou, os entrevistados também apontaram que a prática dos profissionais com relação à amamentação ainda precisa de esforços para avançar mais.

[...] eu acho que os profissionais precisam ser mais preparados nesse sentido, em tá informando a mulher dos benefícios e tá vendo com ela qual é o interesse dela em amamentar [...]. (04)

Ainda estamos engatinhando, é de maneira rudimentar que estamos iniciando [...] após a capacitação de todos os profissionais, acredito que terá de forma mais intensificada esse trabalho. (18)

[...] o que falta, realmente, é incorporar a questão da importância do aleitamento. (22)

[...] há necessidade, realmente, de uma ênfase maior e de até um treinamento maior, não só de médicos, como enfermeiros, ou qualquer profissional que esteja vinculado ou em contato com os pacientes que acabaram de ter filhos, que estão nessa fase de amamentação. (23)

[...] nós precisamos melhorar 0 índice de amamentação [...]. (26)

Para alguns profissionais é a categoria médica que mais precisa melhorar suas condutas com relação à amamentação, como mostram as falas abaixo:

[...] os médicos deveriam despender mais tempo para orientação à amamentação [...] é muito pouco tempo que se gasta com isso. (31) [...] mas ainda nós precisamos melhorar muito muito.... especialmente nós, os médicos [...] a classe médica ainda precisa se conscientizar [...]. (08)

Algumas falas revelaram que as deficiências nas ações em amamentação ainda são preponderantes na atenção básica.

[...] do ponto de vista da promoção, apoio e incentivo ao aleitamento materno a gente vê de uma maneira muito precária, infelizmente [...]. (03)

[...] mas ainda é bastante deficitário, têm muitas falhas ainda. (10)

[...] outros (profissionais) não mudaram seus comportamentos e atitudes (após sensibilização da equipe) (45)

No serviço de atenção básica é muito precário [...]. (53)

A promoção e o apoio à amamentação parecem ocorrer de forma muito heterogênea entre os profissionais, pois de acordo com os entrevistados, não há uma conduta unificada entre os membros da equipe de saúde e sim condutas individuais de cada profissional.

Eu acho que não tem uma conduta única e isso seria importante [...]. (37)

[...] uma maneira bastante desuniforme. Têm grupos que têm uma atitude, outros têm outras, então, não têm uma coerência, uma uniformidade nas orientações. (32)

Eu acho que é muito deficiente a promoção da amamentação [...] em equipe é muito deficiente, ainda é mais individual (48)

Concordamos com Oliveira e Gomes ${ }^{(8)}$ quando afirmam que são "necessários treinamentos iniciais, monitoramento nas situações de renovação das equipes e investimento permanentes na educação continuada dos profissionais" que devem envolver os profissionais através de uma programação sistemática e abrangente.

Acreditamos que para a implementação de ações de promoção e apoio à amamentação entre os profissionais na atenção básica há necessidade além de cursos de formação para os profissionais, o estabelecimento de metas a serem alcançadas pelas equipes que possam ser constantemente avaliadas. Os profissionais entrevistados percebem que com os programas educativos iniciais já houve uma melhora nas ações da atenção básica, porém, há necessidade de se dar continuidade a uma programação mais sistemática e uniforme que 
inclua todos os profissionais e todas as unidades de saúde. Parece que este é o caminho que a gestão municipal da saúde está trilhando ao propor a implantação da IUBAAM nas unidades de atenção básica de São Carlos.

\section{Conhecimento dos profissionais sobre amamentação}

O percentual médio de acerto em todas as 08 questões tipo verdadeiro ou falso, entre as diferentes categorias profissionais foi: enfermeiras, $92,2 \%$ de acertos; médicos pediatras, $88.1 \%$; médicos de família, $86,7 \%$ e médicos ginecologistas e obstetras, $63,6 \%$. As duas categorias que obtiveram um melhor desempenho no teste de conhecimentos foram as de profissionais que mais relataram ter cursado duas capacitações ou mais na área: médicos pediatras $(57,9 \%)$ e enfermeiras $(50 \%)$.

Quanto ao conhecimento específico sobre as diferentes variáveis estudadas referentes à amamentação, os resultados apresentados na Tabela 3 mostram que o tema mais conhecido pelos profissionais é sobre a utilização de chupetas durante a amamentação, pois ao ouvirem a afirmação: “o uso de chupetas pode prejudicar a amamentação", 94,2\% dos profissionais acertaram ao considerarem tal afirmação como verdadeira e 5,8\% erraram quando responderam ser falsa. A categoria que menos acertou a questão sobre este tema foi a de ginecologistas e obstetras. O uso de chupetas, ou bicos artificiais leva à confusão de sucção, ou confusão de bicos que acaba por atrapalhar o bebê predispondo a uma dificuldade de pegar o seio materno.

Tabela 3: Acertos no teste de conhecimento sobre amamentação, por categoria profissional. São Carlos, 2006.

\begin{tabular}{|c|c|c|c|c|c|}
\hline Variáveis & $\begin{array}{l}\text { Enfermeira } \\
\mathrm{N}=16(\%)\end{array}$ & $\begin{array}{c}\text { Médico } \\
\text { pediatra } \\
\mathbf{N}=\mathbf{1 9}(\%)\end{array}$ & $\begin{array}{c}\text { Médico } \\
\text { ginecologista e } \\
\text { obstetra } \\
\mathbf{N}=1 \mathbf{1 3}(\%)\end{array}$ & $\begin{array}{l}\text { Médico de } \\
\text { família } \\
N=6(\%)\end{array}$ & $\begin{array}{c}\text { Total } \\
\mathrm{N}=54(\%)\end{array}$ \\
\hline $\begin{array}{l}\text { Importância de se lavar os } \\
\text { mamilos após a mamada }\end{array}$ & 100 & 94,7 & 61,5 & 83,3 & 87 \\
\hline $\begin{array}{c}\text { Importância de se trocar } \\
\text { de mama após cerca de } \\
10 \text { minutos }\end{array}$ & 87,5 & 78,9 & 16,7 & 80 & 67,3 \\
\hline $\begin{array}{l}\text { Necessidade de o bebê ser } \\
\text { amamentado com } \\
\text { regularidade de horários }\end{array}$ & 87,5 & 73,7 & 41,7 & 80 & 71,2 \\
\hline $\begin{array}{l}\text { Uso de chupetas e a } \\
\text { amamentação } \\
\text { Composição do leite }\end{array}$ & 100 & 94,7 & 81,8 & 100 & 94,2 \\
\hline $\begin{array}{c}\text { materno ao longo da } \\
\text { mamada } \\
\text { Necessidade de }\end{array}$ & 93,8 & 89,5 & 46,2 & 66,7 & 77,8 \\
\hline $\begin{array}{l}\text { complementação se não } \\
\text { ocorrer a apojadura em } \\
\text { até } 3 \text { dias após o parto } \\
\text { Necessidade de }\end{array}$ & 93,8 & 84,2 & 90,9 & 83,3 & 88,5 \\
\hline $\begin{array}{c}\text { complementação se } \\
\text { houver diminuição da } \\
\text { produção láctea }\end{array}$ & 93,8 & 94,7 & 70 & 100 & 90,2 \\
\hline $\begin{array}{c}\text { Benefício da luz solar para } \\
\text { a prevenção de trauma } \\
\text { mamilar }\end{array}$ & 81,2 & 94,7 & 100 & 100 & 92,6 \\
\hline
\end{tabular}

As duas questões com o menor percentual de acertos entre os profissionais de uma forma geral estão relacionadas à duração da mamada em cada mama $(67,3 \%)$ e ao tempo de intervalo entre as mamadas (71,2\%).

Mais de $20 \%$ dos profissionais erraram ao concordarem com a afirmação de que "é importante trocar de mama após cerca de 10 minutos de início da mamada, para que o bebê mame as duas mamas". Esta foi a questão que os ginecologistas e obstetras menos acertaram (16\%). Não existe um tempo definido para a amamentação em cada mama e nem a necessidade de $o$ bebê mamar nas duas 
mamas. O que é importante é que a criança esvazie primeiramente uma mama e depois the seja oferecida a outra mama até que ela esteja satisfeita, sem que necessariamente a aceite ou a esvazie. Esta conduta está baseada no conhecimento sobre a composição do leite materno durante a mamada. O leite no início da mamada (leite anterior) é rico em vitaminas, sais minerais e água e o leite ao final da mamada (leite posterior) é rico em proteínas e lipídios ${ }^{(18)}$. Então, a necessidade de o bebê esvaziar a mama é para que ele ingira todos os componentes do leite anterior e posterior durante a mamada.

A composição do leite materno foi tema de um outro teste de conhecimento em que $77,8 \%$ dos profissionais acertaram ao responderem que o leite inicial é diferente do final e $22,2 \%$ erraram, pois consideraram que o leite materno apresenta concentração igual de elementos no início e no fim da mamada. Esta questão foi a que a categoria dos médicos de família menos acertou $(66,7 \%)$.

A afirmação de que "o bebê deve ser amamentado com regularidade: de 2 em 2 horas na primeira mamada e de 3 em 3 daí em diante", foi considerada falsa por $71,2 \%$ dos profissionais que acertaram o teste. $O$ que chama a atenção é que apesar de a amamentação em livre demanda ser uma conduta que vem sendo adotada há vários anos e estar ancorada em conhecimentos produzidos na área, $18,8 \%$ dos profissionais de nível superior entrevistados ainda a desconhecem. Dentre todas as questões, esta foi a que os Pediatras menos acertaram (73,7\%). Cordeiro $^{(19)}$ afirma que o bebê é quem estabelece o horário e o tempo das mamadas, pois o leite materno tem uma digestão rápida, variando entre uma hora e uma hora e meia e que os intervalos entre as mamadas podem ocorrer de uma em uma, de duas em duas, de três em três horas ou maiores, dependendo de cada criança.

A questão com o menor percentual de acertos entre as enfermeiras $(81,2 \%)$ foi referente à afirmação verdadeira de que "a exposição à luz do sol é benéfica para a prevenção de trauma ou fissura mamilar". A exposição ao sol tem sido indicada há vários anos, porém, antes ela era recomendada para a prevenção e também para o tratamento das fissuras. Hoje, não se indica mais para o tratamento das lesões já existentes, pois pelo conhecimento atual de cicatrização de feridas, a recomendação é de tratamento úmido com o objetivo de formar uma camada externa que proteja e evite a desidratação da epiderme ${ }^{(20)}$. Esta mudança pode ter causado dúvidas em alguns profissionais. Por outro lado, esta foi uma das questões que todas as outras categorias mais acertaram.

Uma outra variável referente aos conhecimentos sobre amamentação avaliada entre os profissionais foi a importância de se lavar os mamilos com água e sabão após cada mamada. É importante, ao final de cada mamada, aplicar o próprio leite materno deixando os mamilos secarem livremente e dessa maneira evitar as fissuras ${ }^{(19)}$. Giugliani ${ }^{(20)}$ enfatiza que o uso de sabões, e outros produtos secantes tornam os mamilos mais vulneráveis a lesões. Portanto, não é indicada a lavagem do mamilo com água e sabão após cada mamada, o que respondeu $87 \%$ dos entrevistados. A categoria com menor percentual de acertos foi a dos médicos ginecologistas e obstetras $(61,5 \%)$.

O conhecimento sobre a necessidade de se iniciar a complementação com outro tipo de leite foi avaliado em duas questões. A primeira dizia respeito à necessidade de complementar o leite materno se não ocorrer a apojadura em até três dias após o parto, a qual um total de $88,5 \%$ dos profissionais respondeu corretamente, ou seja, não há necessidade de se iniciar a complementação. A demora da apojadura requer medidas de apoio, mas não de complementação, sobretudo ainda no terceiro dia de puerpério. Este resultado foi mais satisfatório do que o encontrado em outro estudo no qual $64,8 \%$ dos profissionais entrevistados responderam corretamente ${ }^{(9)}$. A segunda questão foi referente à afirmação de que "se houver diminuição da produção de leite e o bebê der mostras de que está com fome, deve-se iniciar a complementação". Esta afirmação é falsa, pois depois da apojadura, a regulação da produção de leite é feita diretamente nas mamas, com a sucção do bebê. Assim, o volume de leite depende da demanda e é diretamente proporcional ao número de 
mamadas, quanto maior o número de mamadas, maior será o aumento do volume de leite produzido (6). Responderam corretamente $90,2 \%$ dos entrevistados. A categoria com maior percentual de acertos foi a dos médicos de família (100\%) e a com menor foi a dos médicos ginecologistas e obstetras (70\%).

\section{CONCLUSÃO}

O estudo revelou que as concepções sobre amamentação dos profissionais estão voltadas aos benefícios que tal prática proporciona principalmente para a saúde da criança e para os aspectos afetivos e sociais positivos que o aleitamento materno envolve. Quanto à promoção e apoio à amamentação no âmbito dos serviços de atenção básica à saúde, os profissionais acreditam que as ações melhoraram, mas precisam avançar ainda mais. Há a necessidade de unificação das condutas entre os profissionais, pois as ações têm ocorrido de forma muito heterogênea entre os membros da equipe de saúde, com a adoção de condutas individuais.

Tendo em vista os resultados deste estudo de uma forma geral, apesar de a maioria dos profissionais $(94,4 \%)$ se auto-avaliar como capaz de orientar a mãe a melhorar a técnica de amamentação, acreditamos que haja necessidade de se oferecer cursos de atualização sobre o processo de aleitamento materno para que os profissionais possam atuar de forma efetiva na atenção básica. Um percentual expressivo de profissionais $(38,9 \%)$ nunca realizou qualquer curso sobre o tema. A grande maioria dos médicos ginecologistas e obstetras entrevistados $(84,6 \%)$ jamais realizou cursos ou treinamentos nessa área.

As categorias profissionais que apresentaram melhor desempenho nas questões de conhecimento do tipo verdadeiro ou falso foram: a de enfermeira, com uma média de acertos de $92,2 \%$ e a de médico pediatra, com uma média de acertos de $88,1 \%$. E a categoria que obteve desempenho menos satisfatório foi a de médico ginecologista e obstetra que, na maioria dos testes, obteve menor percentual de acertos nas respostas $(63,6 \%)$.

Quanto ao conhecimento e condutas, a questão com o maior percentual de acerto entre os profissionais foi a referente a não utilização de chupetas durante a amamentação (94,2\%). Já as questões mais respondidas de forma incorreta diziam respeito à duração e freqüência da amamentação: $32,7 \%$ dos profissionais responderam que é importante trocar de mama após 10 minutos do início da mamada para que o bebê mame nas duas mamas e $28,8 \%$ que é preciso determinar horários regulares para as mamadas.

Acreditamos que os resultados deste estudo se constituem em indicadores que poderão ser utilizados para o planejamento de cursos de capacitação, bem como para a implantação de novas práticas de promoção e apoio à amamentação nas unidades de atenção básica à saúde.

\section{REFERÊNCI AS}

1. Ministério da Saúde. Organização PanAmericana da Saúde. Guia alimentar para crianças menores de 2 anos. Brasília (Brasil): Ministério da Saúde; 2002.

2. Sena MCF, Silva EF, Pereira MG. Tendência do aleitamento materno no Brasil no último quarto do século $X X$. Rev. bras. epidemiol. 2007; 10(4): 499-505.

3. Rea MF. A amamentação e o uso do leite humano: o que recomenda a Academia Americana de Pediatria. J. Pediatr. (Rio J.). 1998; 74(3): 171-2.

4. Venâncio SI, Escuder MML, Kitoko P, Rea MF, Monteiro CA. Freqüência e determinantes do aleitamento materno em municípios do Estado de São Paulo. Rev. Saúde Pública. 2002;36(3): 313-8.

5. Montrone VG, Arantes CIS. Prevalência do aleitamento materno na cidade de São Carlos. J. Pediatr. (Rio J.). 2000; 76(2): 138-42.

6. Rego JD. Aleitamento Materno: um guia para pais e familiares. São Paulo: Atheneu; 2002.

7. Ministério da Saúde. Manual de Capacitação de equipes de Unidades Básicas de Saúde na Iniciativa Unidade Básica Amiga da Amamentação (IUBAAM). Brasília (Brasil): Ministério da Saúde; 2003.

8. Oliveira MIC, Gomes MA. As Unidades Básicas Amigas da Amamentação: uma nova tática no apoio ao aleitamento materno. In: Rego JD, editor. Aleitamento Materno. São Paulo (SP): Atheneu; 2002. p. 343-366. 
9. Becker D. No seio da família: amamentação e promoção da saúde no Programa de Saúde da Família [dissertation]. Rio de Janeiro: Escola Nacional de Saúde Pública da Fundação Oswaldo Cruz; 2001.

10. Minayo MCS, organizadora. Pesquisa social: teoria, método e criatividade. Petrópolis: Vozes; 1994.

11. Minayo MCS. O desafio do conhecimento: pesquisa qualitativa em saúde. 10th ed. São Paulo: Hucitec; 2007.

12. Bassichetto KC, Rea MF. Aconselhamento em alimentação infantil: um estudo de intervenção. J. Pediatr. (Rio J.). 2008; 84(1): 7582.

13. Martins Filho J. Como e porque amamentar. São Paulo: Savier; 1984.

14. Lopes PRA. As vantagens da amamentação. Por que amamentar? In: Rego JD, editor. Aleitamento Materno. São Paulo: Atheneu; 2002. p. 5-21.

15. Arantes CIS. Amamentação: visão das mulheres que amamentam. J. Pediatr. (Rio J.). 1995; 71(4): 195-202.

16. Ramos CV, Almeida JAG. Alegações maternas para o desmame: estudo qualitativo. J. Pediatr. (Rio J.). 2003; 79(5): 385-90.

17. Nakano AMS. As vivências da amamentação para um grupo de mulheres: nos limites de ser "o corpo para o filho" e de ser "o corpo para si". Cad. Saúde Pública.2003; 19 (Suppl): S355-63.

18. Moura EC. Nutrição. In: Carvalho MR, Tamez RN, editores. Amamentação: bases científicas para a prática profissional. Rio de Janeiro: Guanabara Koogan; 2002. p. 60-87.

19. Cordeiro MT. Manejo da amamentação Posição e pega adequadas: bom início para o sucesso. In: Rego JD, editor. Aleitamento Materno. São Paulo: Atheneu; 2002. p. 47-73.

20. Giugliani ERJ. Falta de embasamento científico no tratamento dos traumas mamilares. J. Pediatr. (Rio J.). 2003; 79(3): 1978.

Artigo recebido em 17.04.08.

Aprovado para publicação em 31.12.08. 